\title{
Patient Organ Radiation Doses During Treatment for Aneurysmal Subarachnoid Hemorrhage
}

Michael Sandborg, Jonas Nilsson Althén, Håkan Pettersson and Sandro Rossitti

\section{Linköping University Post Print}

N.B.: When citing this work, cite the original article.

The original publication is available at www.springerlink.com:

Michael Sandborg, Jonas Nilsson Althén, Håkan Pettersson and Sandro Rossitti, Patient Organ Radiation Doses During Treatment for Aneurysmal Subarachnoid Hemorrhage, 2012, Clinical neuroradiology.

http://dx.doi.org/10.1007/s00062-012-0147-0

Copyright: Springer Verlag (Germany) http://www.springerlink.com/?MUD=MP

Postprint available at: Linköping University Electronic Press http://urn.kb.se/resolve?urn=urn:nbn:se:liu:diva-78917 
Patient organ radiation doses during treatment for aneurismal subarachnoid hemorrhage

Michael Sandborg ${ }^{1}$, Jonas Nilsson Althén ${ }^{1}$, Håkan Pettersson ${ }^{1}$, and Sandro Rossitti ${ }^{2}$

${ }^{1}$ Medical Physics, Department for Medical and Health Sciences, Centre for Medical Image Science and Visualization (CMIV), Linköping University, County Council of Östergötland SE-58185 Linköping, Sweden, University Hospital, SE-58185 Linköping, Sweden

${ }^{2}$ Department of Neurosurgery, County Council of Östergötland, SE-58185 Linköping, Sweden

Corresponding author: Michael Sandborg, Department of Medical Physics, IMH, Linköping University, SE-58185 Linköping, Sweden, phone +46 10 1034007, fax +46 101032895, email michael.sandborg@liu.se 


\begin{abstract}
Purpose: The aim of this retrospective study was to estimate risk organ doses and to estimate radiation risks during the imaging work-up and treatment for aneurismal subarachnoid hemorrhage, SAH.

Methods: The imaging procedures comprised computed tomography and digital subtraction angiography studies done for diagnosis or endovascular interventional procedures in 50 consecutive patients. Equivalent organ doses $\mathrm{H}_{\mathrm{T}}$ to skin, brain, eye lens, salivary glands, thyroid and oral mucosa were measured using thermo-luminescence dosimeters in an anthropomorphic head phantom. PACS and RIS records were analyzed and the frequency of each imaging procedure was recorded as well as the registered individual kerma-length product, $\mathrm{P}_{\mathrm{KL}}$, and the kerma-area product, $\mathrm{P}_{\mathrm{KA}}$. The doses were finally computed by multiplying the recorded $\mathrm{P}_{\mathrm{KL}}$ and $\mathrm{P}_{\mathrm{KA}}$ values by the conversion coefficients $\mathrm{H}_{\mathrm{T}} / \mathrm{P}_{\mathrm{KL}}$ and $\mathrm{H}_{\mathrm{T}} / \mathrm{P}_{\mathrm{KA}}$ from the head phantom.

Results: The mean fluoroscopy time, $\mathrm{P}_{\mathrm{KL}}$ and $\mathrm{P}_{\mathrm{KA}}$ were $38 \mathrm{~min}, 7269 \mathrm{mGy} \mathrm{cm}$ and 286 Gy $\mathrm{cm}^{2}$, respectively. The estimated mean equivalent doses were as follows: skin $2.51 \mathrm{~Sv}$, brain $0.92 \mathrm{~Sv}$, eye lens $0.43 \mathrm{~Sv}$, and salivary glands $0.23 \mathrm{~Sv}$. Maximum organ doses were 2.3 -3.5 times higher than the mean. Interventional procedures contributed $66 \%$ to skin dose, $55 \%$ to brain dose and $25 \%$ to eye lens dose. Of the patients that had an estimated skin dose exceeding $6 \mathrm{~Sv}$, only one patient developed temporary epilation.

Conclusion: The risk for radiation-induced cancer for SAH patients is low (2-3 cases per 1000 patients, of which $90 \%$ are expected to be of benign type) compared with the risk of tissue reactions on the head such as skin erythema and epilation (1 temporary epilation per 50 patients).
\end{abstract}

Key words Endovascular intervention, subarachnoid hemorrhage, radiation risks, tissue reaction, risk organ (eye lens, brain, skin) doses 


\title{
Introduction
}

Subarachnoid hemorrhage (SAH) resulting from rupture of an intracranial saccular aneurysm has been found to occur with a frequency of between 8.1 and 23 per 100,000 in communitybased studies, most commonly in patients aged 40 to 60 years (mean age about 50 years), and it is 1.6 times more frequent in women than in men. In spite of considerable advances in diagnostic methods, endovascular and surgical techniques and per-operative management, aneurismal SAH is still a devastating condition, with population-based mortality rates as high as $45 \%$ and significant morbidity among survivors [1].

Technological advancements in medical imaging that improved diagnosis and made endovascular therapy possible resulted in decreased mortality and morbidity, but also resulted in patients with aneurismal SAH receiving more medical radiation centered on the head than ever before. Even if the ALARA (as low as reasonably achievable) concept of using only enough radiation to obtain images of sufficient quality for diagnosis or intervention is respected in individual imaging studies, the cumulative biological effects of increased number and complexity of x-ray-based medical imaging sessions in the first two weeks after SAH may become a concern for the survivors. The radiation risks are acute (deterministic) radiation effects (tissue reactions) as defined by ICRP [2], and radiation-induced cancer (stochastic risk) [3]. Assessment of these biological effects is particularly important when new imaging techniques, such as Computed Tomography, CT perfusion for the evaluation of cerebral blood flow in patients with vascular disorder [4], are established. In view of the revised recommendations by the ICRP [5] including consideration of the detriment arising from non-cancer effects of radiation on health, it is essential to optimize radiological protection to minimize tissue reactions, such as skin erythema, temporary epilation and late manifested eye lens reactions. According to ICRP [2] acute radiation doses, delivered to tissues during a single procedure or closely spaced procedures in time, may cause erythema or cataract at $2 \mathrm{~Sv}$ (organ equivalent dose), permanent epilation at $7 \mathrm{~Sv}$, and delayed skin necrosis at $12 \mathrm{~Sv}$.

Gelfand and Josephson [6] estimated effective doses to patients with SAH but did not estimate inner organ doses, which may be essential as the dose gradient can be large during the intervention, but also in CT. Mamourian et al. [7] and Moskowitz et al. [8] measured the dose to the skin of SAH patients. However, neither of these studies estimated both skin dose and inner organ dose to organs at risk, such as the brain, salivary glands, oral mucosa and thyroid using a range of different imaging equipment for which tabulated organ doses are not readily available.

This retrospective study was conduced in a geographically well-defined population setting of 50 sequential patients with ruptured intracranial saccular aneurysms treated with endovascular techniques. The aim was to estimate (i) the cumulative doses to organs at risk (skin, brain, salivary glands, oral mucosa, eye lens, and thyroid) by both interventional and CT procedures during the acute, imaging-intensive phase of the therapy for aneurismal subarachnoid hemorrhage and (ii) to estimate short- and long-term radiation effects.

\section{Materials and methods}

\author{
Study Population
}


The Department of Neurosurgery at Linköping University Hospital provides all neurosurgical care to a population of 994,033 in South-Eastern Sweden. Fifty consecutive patients with subarachnoid hemorrhage (SAH) caused by ruptured intracranial saccular aneurysms, which were occluded using endovascular coiling to avoid re-bleeding, were treated at the Neurosurgical Intensive Care Unit (NSICU) after hemorrhage before discharge to local hospitals for continued medical treatment and rehabilitation. The management protocol included ultra-early patient referral (usually within 1-2 hours) from local hospitals after diagnosis of SAH, short-term antifibrinolytic treatment (tranexamic acid), computed tomography (CT) of the head, repair of the ruptured aneurysm as early as logistically feasible, and intensive care. All patients were admitted to the NSICU for prevention and management of hydrocephalus, cerebral vasospasm, ischemia, and systemic complications. Transcranial Doppler (TCD) monitoring of the blood flow velocities at the middle cerebral arteries was done on a daily basis. Decision of whether to use external ventriculostomy, induced hypervolemia, hemodilution, and hypertension was taken on individual merits for each case.

\section{Diagnostic Imaging Work-Up}

The routine imaging work-up included CT on arrival at the emergency ward for SAH diagnosis and computed tomographic angiography (CTA) for aneurysm diagnosis and 3D depiction. Digital subtraction angiography (DSA) was used instead of CTA for aneurysm diagnosis in a few cases. CT was performed within one day of aneurysm repair in most cases and was repeated as necessary in cases with clinical deterioration and in most cases at discharge from the NSICU. All sedated patients underwent a head CT scan 4-12 hours after aneurysm occlusion. CT was carried out on follow-up when hydrocephalus development was suspected. Quantitative studies of cerebral blood flow (CBF) using xenon (Xe)-computerized tomography (Xe-CT) was performed in patients with suspected vasospasm, and to monitor CBF for decision-making in unconscious patients with established severe vasospasm [9-10]. CT on arrival and CTA were performed using a conventional CT scanner (General Electric Lightspeed 16 and Lightspeed Ultra 8, Piscataway, NJ, USA). During NSICU care, bedside $\mathrm{CT}$ and Xe-CT were performed using a mobile CT scanner (CereTom, Neurologica, Boston, USA).

\section{DSA and Endovascular Procedures}

Digital subtraction angiography (DSA) and endovascular procedures were performed on a biplane angiography system (Artis BA or Artis zee Biplane Twin, with additional support of a workstation Syngo X Workplace; from Siemens, Erlangen, Germany) with 3D rotational angiography (3D RA) capability (in the case of Artis zee Biplane Twin also with flat detector $\mathrm{C}$-arm volume acquisition, or DynaCT). Endovascular aneurysm coiling was carried out in accordance with previously described techniques [11]. Endovascular coiling alone, balloonassisted coiling, or stent-assisted coiling was performed as necessary. Imaging during the coiling procedure included 3D rotational angiography in the cases when CTA was not done before, when the CTA study was unsatisfactory for planning the procedure, or for use in 3D road-mapping (iPilot functionality) when demanded by the complexity of the aneurysm [12]. DynaCT was done either before treatment in patients that arrived in general anesthesia and who did not undergo repeated CT or CTA in order to evaluate for re-bleeding or hydrocephalus development during transport from another hospital, or directly after treatment when per-procedural re-bleeding or (based on pericallosal artery and deep cerebral vein 
topography) huge progress of hydrocephalus was suspected (in this case an external ventriculostomy could be placed immediately). Patients with vasospasm were treated with intraarterial injections of Nimodipine associated to balloon angioplasty, when necessary. Nimodipine injections were carried out in the internal carotid or vertebral arteries presenting with vasospasm. For injection in the carotid circulation the angiography catheter was positioned as distal as necessary into the internal carotid artery to avoid reflux to the external carotid artery. For injection into the vertebral artery the catheter was positioned at the level of the vertebra C-III. Nimodipine $0.2 \mathrm{mg} / \mathrm{mL}$ (Nimotop ${ }^{\circledR}$, Bayer) was used for intra-arterial injection diluted in $0.9 \%$ saline in the proportion 1:3; that is $1 \mathrm{mg}$ Nimodipine was diluted in $20 \mathrm{~mL}$ solution. Nimodipine was injected in a coaxial conector through the angiography catheter in small boluses of $1 \mathrm{~mL}$ of the solution every 30 seconds that was washed into the vessel by continuous infusion of saline and Heparine $(1,000 \mathrm{E} / \mathrm{L})$. The target Nimodipine dose for every treated vessel was $3 \mathrm{mg}$, but lower doses ( 1 to $2 \mathrm{mg}$ ) were given in case of mild vasospasm. Inotropic drugs were given i.v. as necessary during intra-arterial Nimodipine treatment. A DSA run of the target vessel was done before and after Nimodipine injection. Balloon angioplasty was carried out as necessary and according to standard techniques [13], and always as a complement to Nimodipine injection in spastic segments of the carotid siphon, proximal middle cerebral artery (M1 and M2 segments), proximal anterior cerebral artery (A1 segment), basilar artery, and proximal posterior cerebral artery (P1 and P2 segments). The balloon system used was the Hyperglide (Micro Therapeutics, Irvine, CA, USA) of size $4 \times 10 \mathrm{~mm}$ in most of the cases, and recently also of size $3 \times 10 \mathrm{~mm}$ when the carotid siphon was not the target vessel. Systemic heparinization was used to keep activated clotting time between 200 and 250 seconds during balloon angioplasty. Heparinization was discontinued but not reversed at the end of the procedure.

\section{Dosimetry Protocol}

Thermo-luminescence dosimeters, TLD $\left(\mathrm{Li}_{2} \mathrm{~B}_{4} \mathrm{O}_{7}\right)$, were used to estimate organ doses in patients and in an anthropomorphic phantom. Dosimeter readout followed a standard protocol for our laboratory using a Rados Dosacus RE-1 reader (Rados Technology Oy, Finland). Before readout the dosimeters were post-annealed at $80{ }^{\circ} \mathrm{C}$ and readout was performed at $300^{\circ} \mathrm{C}$; $0.5 \mathrm{~s}$ preheat, $10.5 \mathrm{~s}$ heating and pulse counting, and $10 \mathrm{~s}$ post-heating. The dosimeters were calibrated to measure (i) the superficial personal dose equivalent, $\operatorname{Hp}(0.07)$, using the ISO/IEC N-40 spectrum, and (ii) the depth dose in soft tissue. The $\mathrm{Hp}(0.07)$ calibration is made at the National Dosimetry Standard laboratory of the Swedish Radiation Safety Authority, and the depth dose calibration is derived from an internal calibrator (Dosacus calibrator, Rados Technology Oy) with a calibration traceable to the National Dosimetry Laboratory of the Radiation and Nuclear Safety Authority, Finland. The uncertainty in the calibration procedure was estimated to be less than $15 \%$ with a $95 \%$ confidence interval.

\section{Patient and Anthropomorphic Phantom Dosimetry}

Inner organ doses cannot be measured directly in patients, so a female anthropomorphic phantom [14] (body mass $55 \mathrm{~kg}$, length $160 \mathrm{~cm}$ ) was used to estimate the doses from CT and intervention procedures. Absorbed doses in the risk organs of skin, brain, salivary glands, oral mucosa, thyroid, and eye lens were estimated by positioning TL dosimeters in the phantom. Two or four dosimeters were positioned in at least 37 dedicated holes in the head phantom representing particular risk organs. Dosimeter positions for the eye lens ( 2 positions) and 
thyroid ( 2 positions) were already present in the phantom; new positions were created for the brain ( 22 positions), salivary glands ( 9 positions), and oral mucosa (5 positions) in consultation with a specialist in odontological imaging. In the phantom, the tissue/organ equivalent doses $\mathrm{H}_{\mathrm{T}}$ were computed for these risk organs after they had been imaged with the same imaging protocol as for the patients. The anthropomorphic head phantom was hence imaged with both flat-detector CT (DynaCT) using the Siemens biplane angiography system, with two different conventional General Electric computed tomography systems (CT, CTA) and with one CereTom mobile CT system (CT, Xe-CT) at the NSICU. To simulate the interventional coiling procedure on the head phantom, a coiling procedure was mimicked and the phantom was exposed to both typical fluoroscopy and DSA series and the kerma-area product, $\mathrm{P}_{\mathrm{KA}}$, was also recorded [15]. In the CTA examination, measurement of the organ equivalent dose, $\mathrm{H}_{\mathrm{T}}$, was repeated three times. Three different radiological nurses performed these examinations on the phantom in order to estimate the uncertainty of the head phantom's organ doses due to different staff performing the examination however using the same imaging protocol. The CT dose index $\left(\mathrm{C}_{\mathrm{vol}}\right)$, kerma-length product $\mathrm{P}_{\mathrm{KL}}$, and kerma-area product $\mathrm{P}_{\mathrm{KA}}$ from these phantom measurements are listed in Table 1.

In the DynaCT imaging on the biplane unit, the rotation of the X-ray tube is only 220 degrees, resulting in lower equivalent doses on the anterior side of the head as the X-ray tube rotates under the phantom or patient's neck, which produces a fixed $\mathrm{P}_{\mathrm{KA}}$ of $7973 \mu \mathrm{Gy} \mathrm{m}{ }^{2}$ (or $80 \mathrm{~Gy}$ $\mathrm{cm}^{2}$ ). In the Xe-CT CBF examination, four separate 10-mm-wide sections of the brain were imaged using $\mathrm{a}_{\mathrm{vol}}$ of $25.2 \mathrm{mGy}$ and the series were repeated eight times per session. A 10mm-wide reference scan with $\mathrm{C}_{\mathrm{vol}}=14.4 \mathrm{mGy}$ was also performed. The conventional $\mathrm{CT}$ and CTA examinations of the head phantom resulted in $\mathrm{C}_{\mathrm{vol}}$ and $\mathrm{P}_{\mathrm{KL}}$ values as shown in Table 1 . Note that our imaging protocol of CT brain uses a higher $\mathrm{C}_{\mathrm{vol}}$ in the cerebellum $(40 \mathrm{~mm}$ scan length) than in the brain ( $88 \mathrm{~mm}$ scan length) as axial scanning was used here.

During the interventional coiling procedure, DynaCT imaging was performed on some patients as described above. The maximum skin and eye lens doses were measured using a headband holding eight pairs of TL dosimeters for ten patients. These measurements were performed using the same technique as described by Sandborg et al [15].

The hospital PACS (Picture archiving and communication system) and RIS (Radiological information system) patient dose records were analyzed for the 50 patients starting from the time when the patient was admitted to hospital for $\mathrm{SAH}$ and ending when the patient was discharged from NSICU. The individual patient dose records in terms of $\mathrm{C}_{\mathrm{vol}}, \mathrm{P}_{\mathrm{KL}}$, and $\mathrm{P}_{\mathrm{KA}}$ were analyzed including all interventional and $\mathrm{CT}$ procedures during the study period. The individual patient organ equivalent doses were estimated by multiplying a patient's $\mathrm{P}_{\mathrm{KL}}$ and $\mathrm{P}_{\mathrm{KA}}$ (from the PACS/RIS dose records) by the $\mathrm{H}_{\mathrm{T}} / \mathrm{P}_{\mathrm{KL}}$ and $\mathrm{H}_{\mathrm{T}} / \mathrm{P}_{\mathrm{KA}}$ organ dose conversion coefficients from the anthropomorphic phantom measurement (see previous section) using the same imaging protocol and imaging equipment as with the patients (see Table 1).

\section{Results}

\section{Clinical Results}

The patients were 38 women and 12 men with mean age 54 years $(\mathrm{SD}=11.8$; range 20 to 78 years). Aneurysm sites and respective obliteration rates after endovascular treatment are summarized in Table 2. The patient's clinical condition on arrival and outcome are 
summarized in Table 3. Severity of SAH, evaluated on admission with the Hunt and Hess Grade [16], was Grade I in 19 patients, Grade II in 7, Grade III in 2, and Grade IV in 1. Fiftynine aneurysms were treated (three patients had two aneurysms and three patients had three aneurysms that were occluded in the same intervention). The most frequent aneurysm site was the anterior communicating artery (27 aneurysms, or 45.7\%), mean aneurysm size was 5.8 $\mathrm{mm}(\mathrm{SD}=3.2$; range 2 to $19 \mathrm{~mm})$, and 36 aneurysms $(61 \%)$ were wide-necked. All but one patient were treated within 72 hours of SAH (one patient was treated two weeks after SAH, after developing secondary cerebral ischemia due to vasospasm). Coiling alone was performed in 49 aneurysms (83\%), balloon-assisted coiling in 7 (11.9\%), and stent-assisted coiling in $3(5.1 \%)$. The coiling procedure included 3D RA in 19 cases, and the volume acquisition was also used for 3D road-mapping (iPilot) in 7 of these cases but in only one case the lesion (a very small anterior communicating aneurysm) would not be approachable using endovascular technique without this functionality. Immediate aneurysm obliteration on DSA according to the Montréal scale [17] was complete obliteration in 30 aneurysms (50.8\%), a residual neck was present in $26(44.1 \%)$ and a residual aneurysm in $3(5.1 \%$; none of the latter were ruptured aneurysms). There were two cases of procedure-related morbidity (4\%): one patient had a brain ischemic complication, and one patient had an intra-procedural aneurismal rupture during a DSA series done just after deployment of the first coil with a resulting intracerebral hematoma that was evacuated by craniotomy after completion of coiling of the aneurysm. The NSICU care period was in average 14.9 days (SD $=11.66$; range 3 to 89 days). The clinical outcome, rated according to the Glasgow Outcome Scale (GOS) [18] at the latest follow-up evaluation (mean 7.5 months; $\mathrm{SD}=6.3$; range 0.3 to 18 months) was a favorable outcome (GOS 4-5) in 40 patients, a poor outcome (GOS 2-3) in 4 patients, and death (GOS 1) in 6 patients.

\section{Organ doses}

Table 4 shows mean values of patient age, days in treatment, fluoroscopy time, kerma-area product, $\mathrm{P}_{\mathrm{KA}}$ (including coiling procedure, treatment of vasospasm, DSA and DynaCT imaging), and kerma-length product, $\mathrm{P}_{\mathrm{KL}}$ (including all CT, CTA, and Xe-CT). There is a considerable spread in the dosimetric results as indicated by the standard deviation of the mean, the minimum, and the maximum values. With the exception of patient age, the median value is lower than the mean value. This is expected from a positive skewed distribution.

The mean number of conventional CT or CTA examinations of the head was 5.8 per patient during the study period. The corresponding number of Xe-CT was 2.0. DynaCT on the biplane angiography system was used on 0.5 occasions per patient. X-ray examinations of other body parts numbered 1.9 per patient during the study period. These examinations were not on the head region but mainly the thorax (conventional chest $\mathrm{x}$-ray examinations, $\mathrm{CT}$ scans of the thorax or of the cervical spine) and only contributed $0.1 \%$ and $0.6 \%$ to the mean $\mathrm{P}_{\mathrm{KA}}$ and $\mathrm{P}_{\mathrm{KL}}$ values, respectively. These examinations were not included in the risk organ dose estimation.

Table 5 shows the risk organ dose conversion coefficients $\mathrm{H}_{\mathrm{T}} / \mathrm{P}_{\mathrm{KL}}$ and $\mathrm{H}_{\mathrm{T}} / \mathrm{P}_{\mathrm{KA}}$ for the phantom and patient TL dosimeter measurements. The coefficients of variation, $\mathrm{CV}$, in the risk organ dose conversion factors for the CTA examination are approximately $4 \%$ for the brain and oral mucosa, $13 \%$ for thyroid and eye lens, and $20 \%$ for the salivary glands. 
Figure 1 and Table 6 show the mean organ equivalent doses during the study period. The error bars associated with the organ equivalent doses in Figure 1 are based on the measured variation in the conversion coefficients obtained from the three repeated measurements in the anthropomorphic phantom (see Table 5). Here it was assumed that the same variation in the conversion coefficients found in the CTA examination was valid in all four CT examinations. The largest percentage dose variation was found for the eye lens $(11 \%)$ and the smallest for the brain (2\%). This is reasonable since the eye lens is located close to the edge of the X-ray beam and the dose to the eye lens is mainly due to the CT examination and only to a smaller extent due to the coiling intervention. The dose to the brain is not likely to depend appreciably on small variations in head positioning by the radiological nurse because the imaging protocol is the same for all CTA examinations and performed on the same CT scanner.

Table 6 shows that the skin receives the highest equivalent dose, followed by the brain, the eye lens, the salivary glands, the oral mucosa, and the thyroid. As can be seen from the standard deviation of the mean organ equivalent doses in Table 4 and from data in Figure 2, the individual variation in equivalent doses from patient to patient is substantial depending on the individual imaging work-up. The highest doses to the skin, brain, and eye lens were 8.8 $\mathrm{Sv}, 2.8 \mathrm{~Sv}$, and $1.0 \mathrm{~Sv}$, respectively.

Figure 2 shows the variation in organ equivalent doses for the 50 patients in the study. Patients 23, 29-31, 36, and 48 died from the disease and three of these patients $(23,29$, and 36) had among the largest cumulative equivalent doses. Nine of the ten patients with the largest cumulative equivalent doses had more than or equal to $15 \mathrm{CT}$ or Xe-CT examinations during the study period.

Figure 3 shows the mean organ equivalent doses to skin, brain, eye lens, and salivary glands and the corresponding percentages of the respective doses from each type of procedure. The brain receives $55 \%$ of its organ dose from the interventional procedures (including DynaCT) and $35 \%$ and $10 \%$ from the CT and Xe-CT procedures, respectively. The eye lens, however, receives only $25 \%$ of the organ dose from the interventional procedure (including DynaCT) and $71 \%$ and $4 \%$ from the CT and Xe-CT procedures, respectively. Most of the skin dose $(66 \%)$ is due to the interventional procedures.

\section{Risk Assessment}

There are two risk scenarios associated with significant irradiation of patients: the risk for radiation-induced cancer and that for tissue reactions such as skin erythema, epilation, and eye lens opacity or cataract.

The incidence risk for nervous system tumors has been thoroughly evaluated by Preston et al. [19] and Thompson et al. [20]. Their evaluation on cancer incidence for atomic bomb survivors in the extended Life Span Study (LSS-E85), a cohort of about 80,000 people, give crude cancer incidence rates by dose and number of excess nervous system tumors. Based on their data an absolute excess risk of about $0.002-0.003 / \mathrm{Sv}$ was derived. Schwannoma accounts for about $65 \%$, meningioma about $20 \%$ and glioma plus astrocytoma about $10 \%$ of the expected excess cases [19]. The corresponding risk for pituitary tumors is about $10 \%$ of the risk for nervous system tumors [19]. With a mean dose to the brain of $0.92 \mathrm{~Sv}$, the theoretical risk of induction of nervous system tumors is about $0.2-0.3 \%$, i.e. $2-3$ cases per 1000 procedures, of which about $90 \%$ of these are expected to be benign tumors. The 
corresponding risk of induction of thyroid and oral cavity cancers, also derived from atomic bomb survivors' data [20-21], is one to two orders of magnitude lower, as expected from the much lower organ dose levels.

The maximum eye lens dose (1004 mSv) is less than the threshold dose for lens cataract or lens opacity according to ICRP [2] but higher than the threshold dose of $0.5 \mathrm{~Sv}$ for late eye lens reactions recently suggested by the ICRP [5]. Among our patients, 17 (34\%) had an estimated eye lens dose exceeding $0.5 \mathrm{~Sv}$. The estimated maximum skin dose of $8.8 \mathrm{~Sv}$ found here substantially exceeds the threshold of early temporary epilation $(3 \mathrm{~Sv})$ and also the threshold for permanent hair loss (7 Sv). In our material, 14 (28\%) exceed the $3 \mathrm{~Sv}$ threshold, 3 patients $(6 \%)$ exceed the $7 \mathrm{~Sv}$ threshold, but none the $12 \mathrm{~Sv}$ threshold for delayed skin necrosis. However, of these three patients with the highest estimated maximum skin dose, two died from their disease. Among the three surviving patients with the highest estimated radiation doses only $1(2 \%)$ developed temporary epilation (patient \#27, a 50-year old woman who underwent $15 \mathrm{CT}$ or DynaCT examinations, $\mathrm{P}_{\mathrm{KA}}=758 \mathrm{~Gy} \mathrm{~cm}^{2}, \mathrm{P}_{\mathrm{KL}}=11439 \mathrm{mGy} \mathrm{cm}$, $\mathrm{H}_{\mathrm{T}, \text { skin }}=6.5 \mathrm{~Sv}, \mathrm{H}_{\mathrm{T} \text {,brain }}=2.1 \mathrm{~Sv}$ ).

\section{Discussion}

\section{Limitations of this Study}

We did not directly measure patient doses by using a dosimeter on each patient's head, as was undertaken for example by Mamourian et al. [7] in their prospective study. In our retrospective study, however, we included a larger number of patients, and took advantage of the very detailed individual PACS/RIS patient dose records and used anthropomorphic phantoms to mimic real CT and coiling procedures for estimation of organ equivalent doses in inner organs as well. In doing so, we may have overestimated the maximum skin dose, since we added the maximum skin dose from all imaging procedures individually. It is possible that the maximum skin dose from several X-ray examinations does not coincide in the same area on the patient's head, which would lead to overestimation of the maximum skin dose.

The incidence risk for nervous system tumors used here for the SAH-patients should be taken as a rough estimate since it does not consider risk modifications such as gender, age at exposure, and attained age. The mean age of the exposed group of the LSS-cohort is 40.7 years which is lower than that of our study group (53.8 years), which indicate an overestimation of the risk for the SAH-patients. A majority of our patients were female.

\section{Comparison with the literature}

In endovascular procedures radiation dose to the patient depends on the interventionist's experience, the number of DSA runs, fluoroscopy time, and technique parameters (pulse rate, dose per pulse, tube current/tube potential modulation and added cupper filtration). In computed tomography, technical features of the CT scanner such as tube current modulation, tube potential and image quality settings (quality reference mAs, noise index etc.) influence the $\mathrm{C}_{\mathrm{vol}}$ and $\mathrm{P}_{\mathrm{KL}}$. These factors have to be taken in consideration in future comparisons to our data. 
The mean kerma-area product, $\mathrm{P}_{\mathrm{KA}}$, in this study $\left(283 \mathrm{~Gy} \mathrm{~cm}^{2}\right)$ is larger than that in our previous study [15] that was $121 \mathrm{~Gy} \mathrm{~cm}^{2}$. However only $44 \%$ or $123 \mathrm{~Gy} \mathrm{~cm}^{2}$ of the kermaarea product is due to the coiling procedure, $113 \mathrm{~Gy} \mathrm{~cm}^{2}$ is due to treatment of vasospasm including a DSA and $47 \mathrm{~Gy} \mathrm{~cm}^{2}$ is due to the DynaCT procedure. Hence the $\mathrm{P}_{\mathrm{KA}}$ from the coiling procedure alone is in fact identical to the results from our previous study, but lower than reported by Kemerink et al. [22] (228 $\left.\mathrm{Gy} \mathrm{cm}^{2}\right)$. However, in this study (in contrast to Sandborg et al. [15]), the estimated maximum skin doses are higher (Table 6) since we also include skin doses due to CT examinations during the patients' stay at the NSICU.

Cohnen et al. [23] estimated organ doses with an anthropomorphic phantom and TL dosimeters using a similar strategy as in this work for standard CT of the head and for CT angiography. The ratio between the organ dose and kerma-length product $\mathrm{H}_{\mathrm{T}} / \mathrm{P}_{\mathrm{KL}}$ for the brain $(0.064 \mathrm{mSv} / \mathrm{mGy} \mathrm{cm})$ is similar to that in our study (Table 5) in the CT brain examination. However, the corresponding $\mathrm{P}_{\mathrm{KL}}$-normalized organ doses differ from ours for the eye lens and the thyroid: ours is lower for the thyroid but higher for the eye lens. The dose to the eye lens depends on the setup of each patient's head in the CT gantry and whether or not the gantry is angulated away from the eye lens.

Suzuki et al. [24] measured skin dose during neuroembolization using a mesh of 44

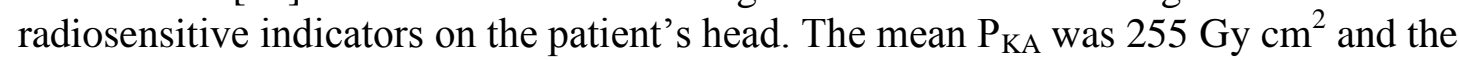
estimated mean maximum entrance skin dose was $1.9 \mathrm{~Gy}$. Their data are slightly higher than the mean maximum skin dose in our survey $(1.7 \mathrm{~Gy})$ from the interventional coiling (including DynaCT) procedure even though the $\mathrm{P}_{\mathrm{KA}}=286 \mathrm{~Gy} \mathrm{~cm}^{2}$ is similar to ours. However, Suzuki et al. [24] suggest that measurement of maximum skin dose with TL dosimeters is likely to underestimate the maximum skin dose owing to the limited number of data points.

Mamourian et al. [7] measured the cumulated skin dose in 12 patients admitted with SAH using a self-developing film badge placed behind the right ear. They found good correlation between the measured dose and the number of CT examinations and length of stay in the ICU. The mean dose for patients with interventional treatment was 0.9 Gy with a maximum of 1.8 Gy for a patient who had 10 CT scans. Our results suggest that the maximum skin dose can be higher, since the mean maximum skin dose was $2.5 \mathrm{~Sv}$ in our study. Here, 17 (34\%) patients had more than $10 \mathrm{CT}$ or DynaCT imaging procedures. A large fraction of the skin dose is due to the coiling procedure (see figure 3 ) and the maximum skin dose is therefore likely to be located on the back of a patient's head.

Moskowitz et al. [8] estimated that the mean cumulative dose to the cranium during hospitalization is 12.8 Gy (range 2.4-36.1 Gy), which is approximately five times higher than the mean maximum skin dose in our study. However, Mamourian et al. [25] have raised some doubts over the data analysis in the work by Moskowitz et al. [8].

Gelfand and Josephson [6] reported a mean effective dose of $80 \mathrm{mSv}$ for $20 \mathrm{SAH}$ patients who had multiple exposures to their head from CT, CTA, cerebral angiography, and interventions. Our estimated mean effective dose, based on organ doses to risk organs measured in this work, was $13 \pm 9 \mathrm{mSv}$ (range 3-39 $\mathrm{mSv}$ ) using the ICRP [21] tissue weighting factors, $\mathrm{w}_{\mathrm{T}}$. However, the effective dose based on the previous compilation of $\mathrm{w}_{\mathrm{T}}$ from year 1991 [26] was approximately 1.8 times higher since the brain would then be a so called 'remainder organ' with a high dose and as such receive a higher tissue weighting factor $\left(\mathrm{w}_{\text {brain }}=0.025\right)$ than when 
using ICRP [21] $\mathrm{w}_{\text {brain }}=0.01$. The use of the effective dose concept in such a small population and with only a small part of the body exposed to high doses is however debatable.

Magrassi et al. [27] estimated the maximum skin dose in 107 consecutive patients who had neuroembolization and found that 22 patients developed partial epilation on average 4 weeks after the procedure. This corresponds to one case of epilation in five neuroembolizations which is a more frequent occurrence compared to our study. However their follow-up strategy for tissue reactions was more careful than ours but their median $\mathrm{P}_{\mathrm{KA}}\left(957 \mathrm{~Gy} \mathrm{~cm}^{2}\right)$ is larger than our corresponding $95 \%$-percentile value $\left(809 \mathrm{~Gy} \mathrm{~cm}^{2}\right)$. From their extensive literature study, the average maximum skin dose at which epilation developed was 4.2 Gy (range 2.0$6.6 \mathrm{~Gy}$ ), indicating that, as in our study, tissue reactions do occur following justified, highdose procedures.

\section{Importance from a clinical perspective}

Since a large proportion of our patients (80\%) made a good recovery or had moderate disability on follow-up, the risk for developing tissue reactions may be a matter of concern. However, aneurismal subarachnoid hemorrhage is a life-threatening condition and in the process of obtaining informed consent from the patient or his/her family for treatment it would be unreasonable to emphasize the potential deterministic and especially the stochastic effects of the radiation dose involved. Radiation effects are not observed in most patients. On the other hand an uninformed patient may not know whom to turn to in the event of skin erythema or temporary epilation in the weeks following treatment. One strategy can be to provide some general information to the patients and to assess the occurrence of skin reaction as part of the clinical follow-up, in particular to those individuals who are more likely to develop tissue reactions owing to a high dose at the interventional reference point $(>4,000$ mGy) from the interventional examination, or who have had more than $15 \mathrm{CT}$ examinations ( $10 \%$ of the patients in this study). Replacement of CT with MRI is not realistic as method for dose reduction in patients in the acute phase of aneurismal SAH, because of the risks inherent in the transport of severely ill, multimodality monitored patients, and the fact that CT scans can be obtained in the bedside [28].

The radiation dose during the endovascular procedures represents only a minor share of the total radiation dose during hospitalization for aneurismal SAH, and the possibilities to reduce per-procedural dose are limited: the kerma-area product was in average only $123 \mathrm{~Gy} \mathrm{~cm}^{2}$ in the coiling procedures alone (including the radiation coming from 3D RA but excluding that from DynaCT, when used). A relation between aneurysm complexity and radiation dose is intuitively expected to occur in elective cases involving long procedures using a combination of balloon-assisted technique, stents, and coiling. However, this kind of procedure is usually not the case when we repair a ruptured aneurysm because the use of antiplatelet medication is imperative. In our centre microsurgery is the first choice method for repair of very complex ruptured aneurysms, and a partial coiling procedure that is on empirical basis enough to avoid re-bleeding is done when microsurgery is considered a less good method for the particular situation. We use stent-assisted coiling in patients with acute SAH only in exceptional cases: in this series 2 of the 3 patients treated with stent-assisted coiling had complex aneurysms but only mild SAH without hydrocephalus in the first CT scan, and these patients did well; the lesion was considered not approachable by microsurgery and partial coiling alone could not be done in the third case, and that patient had a fatal outcome. 


\section{Conclusion}

The mean skin, brain, and eye lens doses were $2.5 \mathrm{~Sv}, 1.00 \mathrm{~Sv}$, and $0.40 \mathrm{~Sv}$, respectively, but individual patient maximum doses were up to 2.3-3.5 times higher, with some of them well above the threshold for deterministic effects. The theoretical risk for radiation-induced cancer for SAH patients is low (2-3 cases per 1000 patients), of which about $90 \%$ are expected to be of benign type. The risk of tissue reactions on the head such as skin erythema and epilation (1 temporary epilation per 50 patients) is higher.

\section{Acknowledgements}

We thank Magnus Gårdestig and Gudrun Alm Carlsson for calibrating the TLD and for giving valuable comments on the manuscript, respectively. Miriam Rodriguez Catarino, $\mathrm{MD}, \mathrm{PhD}$, performed some of the endovascular procedures. This work was supported by the regional ALF-research fund in Sweden.

\section{References}

1. Bederson JB, Connolly ES Jr, Batjer HH, Dacey RG, Dion JE, Diringer MN, Duldner JE Jr, Harbaugh RE, Patel AB, Rosenwasser RH; American Heart Association. Guidelines for the management of aneurysmal subarachnoid hemorrhage: a statement for healthcare professionals from a special writing group of the Stroke Council, American Heart Association. Stroke. 2009;40:994-1025

2. ICRP publication 85: Avoidance of radiation injuries from medical interventional procedures. ISSN 0146-6453, Ann. ICRP 2000;30:2

3. Brenner D J, Hall E J. Computed Tomography - An increasing source of radiation exposure. N Engl J Med. 2007;357:2277-2284

4. Imanishi Y, Fukui A, Niimi H, Itoh D, Nozaki K, Nakaji S, Ishizuka K, Tabata H, Furuya Y, Uzura M, Takahama H, Hashizume S, Arima S, Nakajima Y. Radiation-induced temporary hair loss as a radiation damage only occurring in patients who had the combination of MDCT and DSA. Eur Radiol. 2005;15:41-46

5. ICRP. Statement on Tissue Reactions. Approved by the Commission on April 21, 2011, ICRP ref. 4825-3093-1464, URL: http://www.icrp.org/docs/ICRP\%20Statement\%20on\%20Tissue\%20Reactions.pdf

6. Gelfand AA, Josephson SA. Substantial radiation exposure for patients with subarachnoid hemorrhage. J Stroke Cerebrovasc Dis. 2011;20:131-133

7. Mamourian AC, Young H, Stiefel MF. Cumulative radiation dose in patients admitted with subarachnoid hemorrhage: a prospective study using a self-developing film badge. AJNR Am J Neuroradiol. 2010;31:1787-1790 
8. Moskowitz S I, Davros W J, Kelly M E, Fiorella D, Rasmussen PA, Masaryk TJ. Cumulative radiation dose during hospitalization for aneurismal subarachnoid hemorrhage. AJNR Am J Neuroradiol. 2010;31:1377-82

9. Hillman J, Sturnegk P, Yonas H, Heron J, Sandborg M, Gunnarsson T, Mellergård P. Bedside monitoring of CBF with xenon-CT and a mobile scanner: a novel method in neurointensive care. Br J Neurosurg. 2005;19:395-401

10. Sturnegk P, Mellergård P, Yonas $H$, Theodorsson A, Hillman J. Potential use of quantitative bedside CBF monitoring (Xe-CT) for decision making in neurosurgical intensive care. Br J Neurosurg. 2007;21:332-339

11. Rossitti S. Endovascular coiling of intracranial aneurysms using bioactive coils: A singlecenter study. Acta Radiol. 2007;48:565-576

12. Rossitti S, Pfister M. 3D road-mapping in endovascular treatment of cerebral aneurysms and arteriovenous malformations. Interv Neuroradiol. 2009; 15: 283-290

13. Jestaedt L, Pham M, Bartsch AJ, Kunze E, Roosen K, Solymosi L, Bendszus M. Efficacy of balloon angioplasty in the treatment of vasospasm after aneurysmal SAH. Clin Neuroradiol 2007;17:180-186

14. ATOM 2002. Adult female phantom handling instructions. CIRS tissue simulating technology, 2428 Almeda Ave, Suite 212, Norfolk, Virginia 23513 USA

(http://www.cirsinc.com, admin@cirsinc.com).

15. Sandborg M, Rossitti S, Pettersson H. Local skin and eye lens equivalent doses in interventional neuroradiology. Eur Radiol. 2010;20:725-733

16. Hunt WE, Hess RM. Surgical risk as related to time of intervention in the repair of intracranial aneurysms. J Neurosurg. 1968;28:14-20

17. Raymond J, Guilbert F, Weill A, Georganos SA, Juravsky L, Lambert A, Lamoureux J, Chagnon M, Roy D. Long-term angiographic recurrences after selective endovascular treatment of aneurysms with detachable coils. Stroke. 2003;34:1398-1403

18. Jennett B, Bond M. Assessment of outcome after severe brain damage. Lancet $1975 ; 1: 480-484$

19. Preston D L, Ron E, Yonehara S, Kobuke T, Fujii H, Kishikawa M, Tokunaga M, Tokuoka S, Mabuchi K. Tumors of the nervous system and pituitary gland associated with atomic bomb radiation exposure. J Natl Cancer Inst. 2002;94:1555-1563

20. Thompson D E, Mabuchi K, Ron E, Soda M, Tokunaga M, Ochikubo S, Sugimoto S, Ikeda T, Terasaki M, Izumi S. Cancer incidence in atomic bomb survivors. Part II: solid tumors, 1958-1987. Radiat Res. 1994;137:S17-S67 [Erratum in: Radiat Res. 1994;139:129]

21. ICRP. The 2007 Recommendations of the International Commission on Radiological Protection. Publication 103. Ann. ICRP 2007;37:2-4 
22. Kemerink G J, Frantzen M J, Oei K, Sluzewski M, van Rooij WJ, Wilmink J, van Engelshoven JM. Patient and occupational dose in neurointerventional procedures.

Neuroradiology. 2002;44:522-528

23. Cohnen M, Wittsack HJ, Assadi S, Muskalla K, Ringelstein A, Poll LW, Saleh A, Mödder U. Radiation exposure of patient in comprehensive computed tomography of the head in acute stroke. AJNR Am J Neuroradiol. 2006;27:1741-1845

24. Suzuki S, Furui S, Matsumaru Y, Nobuyuki S, Ebara M, Abe T, Itoh D. Patient skin dose during neuroembolization by multiple-point measurement using a radiosensitive indicator. AJNR Am J Neuroradiol. 2008;29:1076-1081

25. Mamourian A, O'Shea M, Maidment ADA. Cumulative radiation dose in patients with aneurismal subarachoid hemorrhage. AJNR Am J Neuroradiol. 2010;31:E87-E88 [Letter]

26. ICRP publication 60: Recommendations of the ICRP. Ann ICRP. 1991; 21:1-3

27. Magrassi L, Bongetta D, D'Ercole L, Lisciandro F, Arienta C, Thyrion F Z. Neuroembolization may expose patients to radiation doses previously linked to tumor induction. Acta Neurochir. 2012;154:33-41

28. Gunnarsson T, Hillman J. Clinical usefulness of bedside intracranial morphological monitoring: mobile computerized tomography in the neurosurgery intensive care unit. Neurosurg Focus. 2000;9(5):E5 


\section{List of Tables captions}

(Tables are shown on separate pages below.)

Table 1. X-ray unit, protocol notation, and dose quantities used in imaging patients and anthropomorphic head phantom.

Table 2: Aneurysm site, morphological data (aneurysm size was defined as the maximum lumen size in millimeters, and wide aneurysm neck was defined by a dome-to-neck ratio less than two, or by a neck at least as wide as the parent vessel), and obliteration rates.

Table 3. Hunt and Hess Grade $(\mathrm{H} \& \mathrm{H})$ on admission of the 50 patients with subarachnoid hemorrhage and their clinical outcome (Glasgow Outcome Scale, GOS) at the latest clinical follow-up (mean 7.5 months; $\mathrm{SD}=6.3$; range 0.3 to 18 months).

Table 4. Patient age, days in treatment, fluoroscopy time, total kerma-area product $\mathrm{P}_{\mathrm{KA}}$, and total kerma-length product $\mathrm{P}_{\mathrm{KL}}$ for the 50 patients in this retrospective study.

Table 5. Conversion coefficients between either organ equivalent dose $\left(\mathrm{H}_{\mathrm{T}}\right)$ and kerma-length product $\mathrm{P}_{\mathrm{KL}}$ or kerma-area product $\mathrm{P}_{\mathrm{KA}}$ for six different imaging protocols.

Table 6. Cumulative mean equivalent doses to the $\operatorname{skin}_{\max }$, brain, eye lens, salivary glands, oral mucosa, and thyroid for the 50 patients throughout the study period. The table also gives standard deviation (std) of the mean, median, minimum, and maximum values. 


\section{List of Figures and legends}

(Figures are found on separate pages below.)

Figure 1. Mean organ equivalent doses for the six organs at risk for patients with SAH during their days of treatment at the NSICU. The error bars indicate the estimated uncertainty (one standard deviation) associated with the variation in the conversion coefficient $\mathrm{H}_{\mathrm{T}} / \mathrm{P}_{\mathrm{KL}}$ from three repeated measurements of organ doses in the phantom due to slight changes in the positioning of the anthropomorphic phantom in the CT scanner by different radiological nurses.

Figure 2. Individual organ equivalent doses to the six organs at risk for the 50 patients in this retrospective study. Patient number 6, 29 and 36 were treated for 2 aneurysms and patient number 13, 23 and 48 were treated for 3 aneurysms. These are denoted with ' 2 ' and ' 3 ' in the figure. Note that the sum of the organ equivalent doses in the risk organs (total height of bars) has no meaningful interpretation.

Figure 3. Pie charts of the organ equivalent doses in the skin (a), brain (b), eye lens (c), and salivary glands (d) and the corresponding percentages of the doses due to each type of imaging procedure. 
Table 1. X-ray unit, protocol notation, and dose quantities used in imaging patients and anthropomorphic head phantom.

\begin{tabular}{|l|l|l|l|l|}
\hline X-ray unit & $\begin{array}{l}\text { Protocol } \\
\text { notation }\end{array}$ & $\begin{array}{l}\mathrm{C}_{\mathrm{vol}}^{1} \\
(\mathrm{mGy})\end{array}$ & $\begin{array}{l}\mathrm{P}_{\mathrm{KL}} \\
(\mathrm{mGy} \mathrm{cm})\end{array}$ & $\begin{array}{l}\mathrm{P}_{\mathrm{KA}} \\
\left(\mathrm{Gy} \mathrm{cm}^{2}\right)^{2}\end{array}$ \\
\hline Artis Zee Biplane (Siemens) & DynaCT & - & - & 80 \\
\hline $\begin{array}{l}\text { CereTom (8-slice CereTom } \\
\text { Neurologica) }\end{array}$ & $\begin{array}{l}\text { Xe-CT } \\
(\mathrm{CBF})\end{array}$ & 203 & 821 & - \\
\hline $\begin{array}{l}\text { CereTom (8-slice CereTom } \\
\text { Neurologica) }\end{array}$ & $\mathrm{CT}$ & 59 & 1193 & - \\
\hline $\begin{array}{l}\text { Lightspeed 8 Ultra (General } \\
\text { Electric) }\end{array}$ & $\mathrm{CT}$ & $58,(86)$ & 922 & - \\
\hline Lightspeed 16 Pro (General Electric) & CTA & 61 & 849 & - \\
\hline
\end{tabular}

${ }^{1}$ The $\mathrm{C}_{\mathrm{vol}}$ value in parentheses is used in the cerebellum

$21 \mathrm{Gycm}^{2}=100 \mu \mathrm{Gy} \mathrm{m}{ }^{2}$ 
Table 2: Aneurysm site, morphological data (aneurysm size was defined as the maximum lumen size in millimeters, and wide aneurysm neck was defined by a dome-to-neck ratio less than two, or by a neck at least as wide as the parent vessel), and obliteration rates.

\begin{tabular}{|c|c|c|c|c|c|}
\hline \multirow[t]{2}{*}{ Site } & \multirow{2}{*}{$\begin{array}{l}\text { Ruptured } \\
\text { aneurysms }\end{array}$} & \multirow{2}{*}{$\begin{array}{l}\text { Unruptured } \\
\text { aneurysms }\end{array}$} & \multicolumn{3}{|c|}{ Aneurysm obliteration } \\
\hline & & & Class 1 & Class 2 & Class 3 \\
\hline $\begin{array}{l}\text { Anterior communicating } \\
\text { artery }\end{array}$ & $\begin{array}{l}\mathrm{N}=26 \\
\mathrm{MS}=5 \\
\mathrm{SR}=2.5-8 \\
\mathrm{WN}=14\end{array}$ & $\begin{array}{l}\mathrm{N}=1 \\
\mathrm{~S}=3.1 \\
\mathrm{WN}=0\end{array}$ & $\begin{array}{l}\mathrm{N}=14 \\
\mathrm{WN}=3\end{array}$ & $\begin{array}{l}\mathrm{N}=13 \\
\mathrm{WN}=11\end{array}$ & - \\
\hline Pericallosal artery & $\begin{array}{l}\mathrm{N}=1 \\
\mathrm{~S}=3.1 \\
\mathrm{WN}=1\end{array}$ & - & - & $\begin{array}{l}\mathrm{N}=1 \\
\mathrm{WN}=1\end{array}$ & - \\
\hline $\begin{array}{l}\text { Internal carotid artery (ICA); } \\
\text { proximal, ophthalmic, or } \\
\text { parasellar segment }\end{array}$ & $\begin{array}{l}\mathrm{N}=2 \\
\mathrm{MS}=9.3 \\
\mathrm{SR}=7.1-11.5 \\
\mathrm{WN}=2\end{array}$ & $\begin{array}{l}\mathrm{N}=2 \\
\mathrm{MS}=11.1 \\
\mathrm{SR}=8-14.2 \\
\mathrm{WN}=2\end{array}$ & $\begin{array}{l}\mathrm{N}=2 \\
\mathrm{WN}=2\end{array}$ & $\begin{array}{l}\mathrm{N}=1 \\
\mathrm{WN}=1\end{array}$ & $\begin{array}{l}\mathrm{N}=1 \\
\mathrm{WN}=1\end{array}$ \\
\hline $\begin{array}{l}\text { ICA; posterior communicating } \\
\text { and anterior choroidal } \\
\text { segment }\end{array}$ & $\begin{array}{l}\mathrm{N}=10 \\
\mathrm{MS}=4.6 \\
\mathrm{SR}=2.6-8.5 \\
\mathrm{WN}=5\end{array}$ & $\begin{array}{l}\mathrm{N}=1 \\
\mathrm{~S}=3.6 \\
\mathrm{WN}=0\end{array}$ & $\begin{array}{l}\mathrm{N}=7 \\
\mathrm{WN}=3\end{array}$ & $\begin{array}{l}\mathrm{N}=4 \\
\mathrm{WN}=2\end{array}$ & - \\
\hline ICA bifurcation & $\begin{array}{l}\mathrm{N}=2 \\
\mathrm{MS}=3.3 \\
\mathrm{SR}=3-3.6 \\
\mathrm{WN}=1\end{array}$ & - & $\begin{array}{l}\mathrm{N}=2 \\
\mathrm{WN}=1\end{array}$ & - & - \\
\hline Middle cerebral artery & $\begin{array}{l}\mathrm{N}=3 \\
\mathrm{MS}=4.9 \\
\mathrm{SR}=4.5-5.3 \\
\mathrm{WN}=2\end{array}$ & $\begin{array}{l}\mathrm{N}=5 \\
\mathrm{MS}=5.24 \\
\mathrm{SR}=2-8 \\
\mathrm{WN}=4\end{array}$ & $\begin{array}{l}\mathrm{N}=3 \\
\mathrm{WN}=1\end{array}$ & $\begin{array}{l}\mathrm{N}=3 \\
\mathrm{WN}=3\end{array}$ & $\begin{array}{l}\mathrm{N}=2 \\
\mathrm{WN}=2\end{array}$ \\
\hline Basilar bifurcation & $\begin{array}{l}\mathrm{N}=5 \\
\mathrm{MS}=11.9 \\
\mathrm{SR}=5-19 \\
\mathrm{WN}=4\end{array}$ & - & $\begin{array}{l}\mathrm{N}=2 \\
\mathrm{WN}=2\end{array}$ & $\begin{array}{l}\mathrm{N}=3 \\
\mathrm{WN}=2\end{array}$ & - \\
\hline Basilar trunk & $\begin{array}{l}\mathrm{N}=1 \\
\mathrm{~S}=10 \\
\mathrm{WN}=1\end{array}$ & - & - & $\begin{array}{l}\mathrm{N}=1 \\
\mathrm{WN}=1\end{array}$ & - \\
\hline Total & $\begin{array}{l}\mathrm{N}=50 \\
(84.7 \%)\end{array}$ & $\begin{array}{l}\mathrm{N}=9 \\
(15.3 \%)\end{array}$ & $\begin{array}{l}\mathrm{N}=30 \\
(50.8 \%)\end{array}$ & $\begin{array}{l}\mathrm{N}=26 \\
(44.1 \%)\end{array}$ & $\begin{array}{l}\mathrm{N}=3 \\
(5.1 \%)\end{array}$ \\
\hline
\end{tabular}

$\mathrm{MS}=$ mean aneurysm size (in millimeters); $\mathrm{N}=$ number of aneurysms; $\mathrm{S}=$ aneurysm size (in millimeters); $\mathrm{SR}=$ minimum-maximum size range (in millimeters); $\mathrm{WN}=$ number of aneurysms with wide neck. 
Table 3: Hunt and Hess Grade $(\mathrm{H} \& \mathrm{H})$ on admission of the 50 patients with subarachnoid hemorrhage and their clinical outcome (Glasgow Outcome Scale, GOS) at the latest clinical follow-up (mean 7.5 months; $\mathrm{SD}=6.3$; range 0.3 to 18 months).

\begin{tabular}{|c|c|c|c|c|c|c|}
\hline \multirow{2}{*}{$\begin{array}{c}\mathrm{H} \& \mathrm{H} \\
\text { Grade on } \\
\text { admission }\end{array}$} & \multicolumn{5}{|c|}{ GOS score on follow-up $(\mathrm{N}=50)$} & Total \\
\hline & $\begin{array}{l}\text { GOS 5: } \\
\text { Good } \\
\text { recovery }\end{array}$ & $\begin{array}{l}\text { GOS 4: } \\
\text { Moderate } \\
\text { disability }\end{array}$ & $\begin{array}{c}\text { GOS 3: } \\
\text { Severe } \\
\text { disability }\end{array}$ & $\begin{array}{c}\text { GOS 2: } \\
\text { Chronic } \\
\text { vegetative } \\
\text { state }\end{array}$ & $\begin{array}{c}\text { GOS } \\
\text { 1: } \\
\text { Dead }\end{array}$ & \\
\hline 1 & $\begin{array}{c}19 \\
(38 \%)\end{array}$ & $\begin{array}{c}1 \\
(2 \%)\end{array}$ & $\begin{array}{c}2 \\
(4 \%)\end{array}$ & - & - & $\begin{array}{c}22 \\
(44 \%)\end{array}$ \\
\hline 2 & $\begin{array}{c}7 \\
(14 \%)\end{array}$ & $\begin{array}{c}5 \\
(10 \%)\end{array}$ & $\begin{array}{c}1 \\
(2 \%)\end{array}$ & - & - & $\begin{array}{c}13 \\
(26 \%)\end{array}$ \\
\hline 3 & $\begin{array}{c}2 \\
(4 \%)\end{array}$ & $\begin{array}{c}4 \\
(8 \%)\end{array}$ & - & - & $\begin{array}{c}3 \\
(6 \%)\end{array}$ & $\begin{array}{c}9 \\
(18 \%)\end{array}$ \\
\hline 4 & $\begin{array}{c}1 \\
(2 \%) \\
\end{array}$ & $\begin{array}{c}1 \\
(2 \%) \\
\end{array}$ & $\begin{array}{c}1 \\
(2 \%) \\
\end{array}$ & - & $\begin{array}{c}1 \\
(2 \%) \\
\end{array}$ & $\begin{array}{c}4 \\
(8 \%) \\
\end{array}$ \\
\hline 5 & - & - & - & - & $\begin{array}{c}2 \\
(4 \%)\end{array}$ & $\begin{array}{c}2 \\
(4 \%)\end{array}$ \\
\hline Total & $\begin{array}{c}29 \\
(58 \%) \\
\end{array}$ & $\begin{array}{c}11 \\
(22 \%)\end{array}$ & $\begin{array}{c}4 \\
(8 \%) \\
\end{array}$ & - & $\begin{array}{c}6 \\
(12 \%) \\
\end{array}$ & $\begin{array}{c}50 \\
(100 \%) \\
\end{array}$ \\
\hline
\end{tabular}


Table 4. Patient age, days in treatment, fluoroscopy time, total kerma-area product $\mathrm{P}_{\mathrm{KA}}$, and total kerma-length product $\mathrm{P}_{\mathrm{KL}}$ for the 50 patients in this retrospective study.

\begin{tabular}{|c|c|c|c|c|c|}
\hline & $\begin{array}{l}\text { Patient age } \\
\text { (years) }\end{array}$ & $\begin{array}{l}\text { Days in } \\
\text { treatment } \\
\text { (days) }\end{array}$ & $\begin{array}{l}\text { Fluoroscopy } \\
\text { time } \\
(\min )\end{array}$ & $\begin{array}{l}\mathrm{P}_{\mathrm{KA}} \text { for all } \\
\text { interventions } \\
\text { and DynaCT } \\
\text { imaging } \\
\left(\mathrm{Gy} \mathrm{cm}^{2}\right)^{1}\end{array}$ & $\begin{array}{l}\mathrm{P}_{\mathrm{KL}} \text { for all } \mathrm{CT} \\
\text { examinations } \\
(\mathrm{mGy} \mathrm{cm})\end{array}$ \\
\hline Mean $\pm 1 \mathrm{std}^{2}$ & $53.8 \pm 11.8$ & $14.9 \pm 11.7$ & $37.6 \pm 35.0$ & $286 \pm 251$ & $7.3 \cdot 10^{3} \pm 5.5 \cdot 10^{3}$ \\
\hline Median & 54.5 & 12 & 26.5 & 178 & $4.6 \cdot 10^{3}$ \\
\hline Minimum & 20 & 3 & 5.4 & 45 & $1.7 \cdot 10^{3}$ \\
\hline Maximum & 78 & 89 & 171 & 1069 & $21.3 \cdot 10^{3}$ \\
\hline
\end{tabular}

${ }^{1} 1 \mathrm{Gycm}^{2}=100 \mu \mathrm{Gy} \mathrm{m}{ }^{2}$

2 std: standard deviation 
Table 5. Conversion coefficients between either organ equivalent dose $\left(\mathrm{H}_{\mathrm{T}}\right)$ and kerma-length product $\mathrm{P}_{\mathrm{KL}}$ or kerma-area product $\mathrm{P}_{\mathrm{KA}}$ for six different imaging protocols.

\begin{tabular}{|c|c|c|c|c|c|c|}
\hline & $\begin{array}{l}\text { Mobile } \\
\text { CT }\end{array}$ & $\mathrm{Xe}-\mathrm{CT}$ & CT & CTA $^{1}$ & DynaCT & Coiling $^{2}$ \\
\hline Risk organ & \multicolumn{4}{|c|}{$\mathrm{H}_{\mathrm{T}} / \mathrm{P}_{\mathrm{KL}}(\mathrm{mSv} / \mathrm{mGy} \mathrm{cm})$} & \multicolumn{2}{|c|}{$\mathrm{H}_{\mathrm{T}} / \mathrm{P}_{\mathrm{KA}}\left(\mathrm{mSv} / \mu \mathrm{Gy} \mathrm{m}^{2}\right)$} \\
\hline Skin $_{\max }$ & 0.071 & 0.251 & 0.095 & 0.059 & $0.030^{3}$ & 0.067 \\
\hline Brain & 0.035 & 0.058 & 0.071 & $0.058 \pm 0.002$ & 0.0069 & 0.021 \\
\hline $\begin{array}{l}\text { Salivary } \\
\text { glands }\end{array}$ & 0.0052 & 0.0031 & 0.012 & $0.032 \pm 0.007$ & 0.0055 & 0.0050 \\
\hline $\begin{array}{l}\text { Oral } \\
\text { mucosa }\end{array}$ & 0.0024 & 0.0018 & 0.0052 & $0.0085 \pm 0.0004$ & 0.0036 & 0.0010 \\
\hline Thyroid & 0.00057 & 0.00056 & 0.0022 & $0.0023 \pm 0.0003$ & 0.00037 & 0.00042 \\
\hline Eye lens & 0.052 & 0.0099 & 0.050 & $0.063 \pm 0.009$ & $0.0096^{3}$ & 0.0029 \\
\hline
\end{tabular}

${ }^{1}$ For CTA, the data show the mean $\mathrm{H}_{\mathrm{T}} / \mathrm{P}_{\mathrm{KL}}$ and 1 standard deviation from three repeated measurements.

${ }^{2}$ Data from Sandborg et al [15]

${ }^{3}$ Data from measurements of 10 patients. 
Table 6. Cumulative mean equivalent doses to the $\operatorname{skin}_{\max }$, brain, eye lens, salivary glands, oral mucosa, and thyroid for the 50 patients throughout the study period. The table also gives standard deviation (std) of the mean, median, minimum, and maximum values.

\begin{tabular}{|c|c|c|c|c|c|c|}
\hline $\begin{array}{l}\text { Equivalent } \\
\text { organ doses }\end{array}$ & $\begin{array}{l}\text { Skin }_{\max } \\
(\mathrm{mSv})\end{array}$ & $\begin{array}{l}\text { Brain } \\
(\mathrm{mSv}) \\
\end{array}$ & $\begin{array}{l}\text { Eye lens } \\
(\mathrm{mSv})\end{array}$ & $\begin{array}{l}\text { Salivary } \\
\text { glands } \\
(\mathrm{mSv})\end{array}$ & $\begin{array}{l}\text { Oral } \\
\text { mucosa } \\
(\mathrm{mSv})\end{array}$ & $\begin{array}{l}\text { Thyroid } \\
(\mathrm{mSv})\end{array}$ \\
\hline Mean \pm 1 std & $2511 \pm 2233$ & $916 \pm 689$ & $429 \pm 250$ & $228 \pm 150$ & $72 \pm 44$ & $22 \pm 14$ \\
\hline Median & 1537 & 573 & 312 & 168 & 61 & 16 \\
\hline Minimum & 434 & 203 & 110 & 61 & 16 & 6 \\
\hline Maximum & 8804 & 2805 & 1004 & 626 & 191 & 58 \\
\hline
\end{tabular}




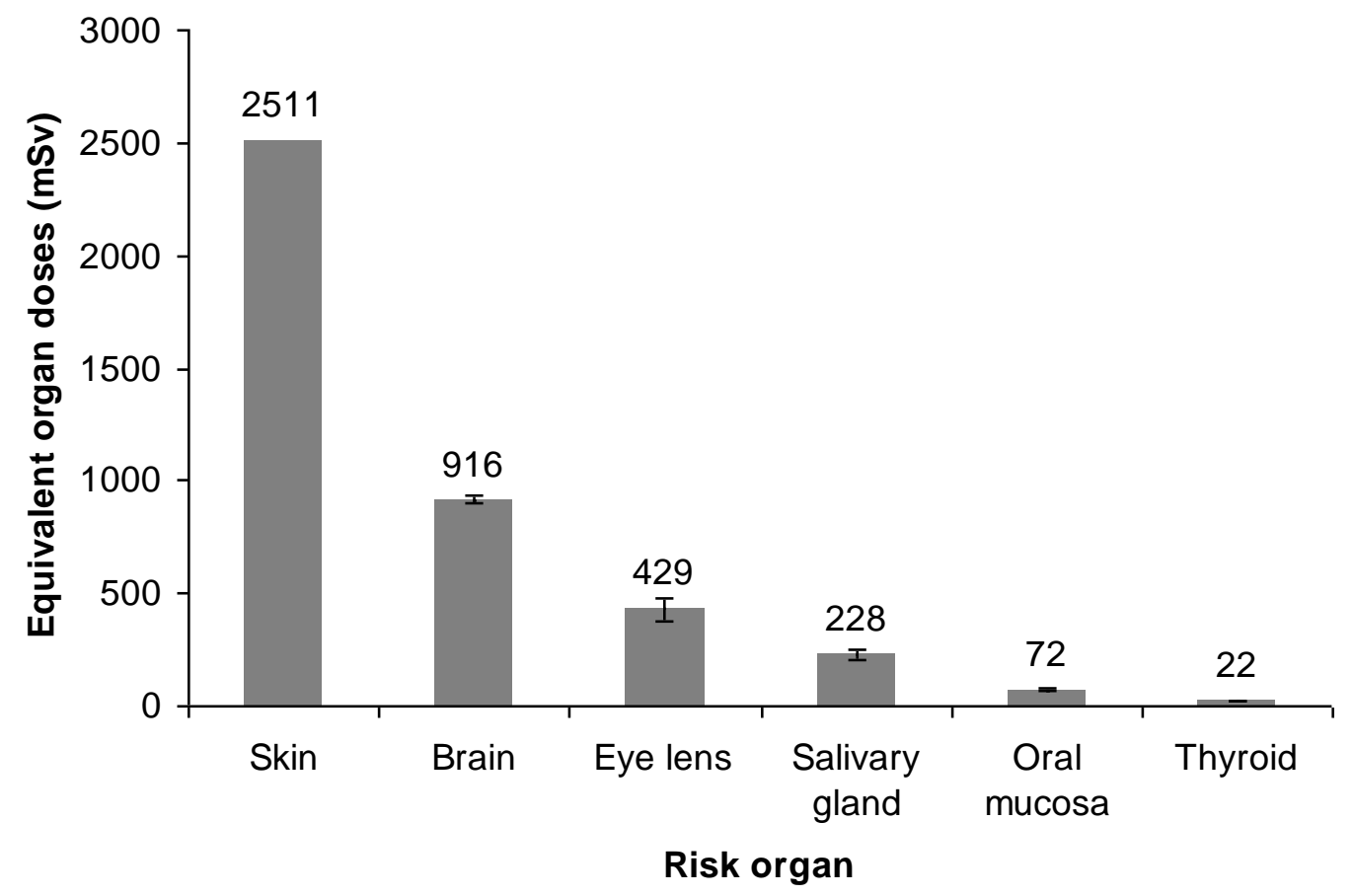

Figure 1. Mean equivalent organ doses for the six organs at risk for patients with SAH during their days of treatment at the NSICU. The error bars indicate the estimated uncertainty (one standard deviation) associated with the variation in the conversion coefficient $\mathrm{H}_{\mathrm{T}} / \mathrm{P}_{\mathrm{KL}}$ from three repeated measurements of organ doses in the phantom due to slight changes in the positioning of the anthropomorphic phantom by different radiological nurses in the CT scanner. 


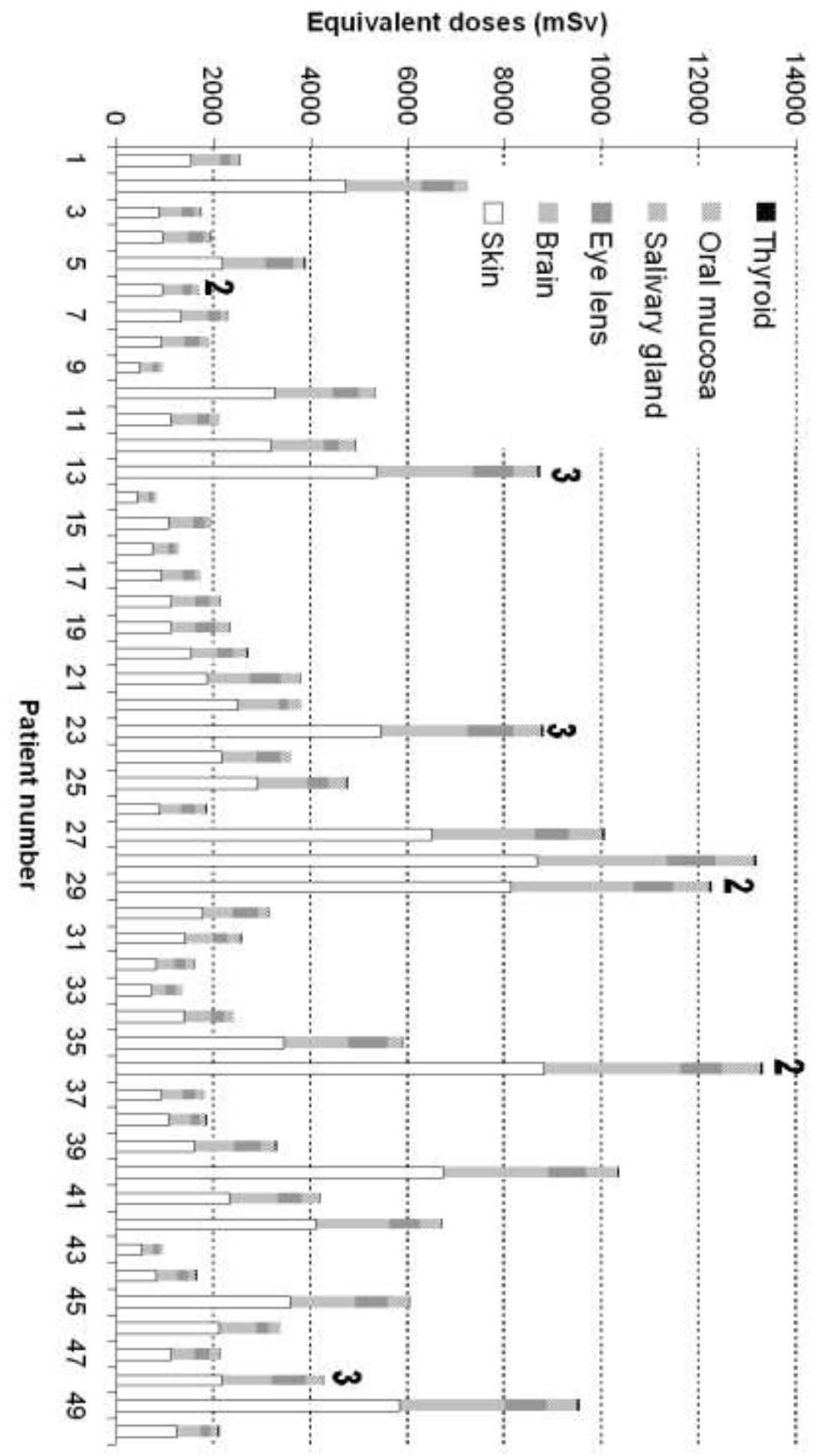

Figure 2. Individual organ equivalent doses to the six organs at risk for the 50 patients in this retrospective study. Patient number 6, 29 and 36 were treated for 2 aneurysms and patient number 13, 23 and 48 were treated for 3 aneurysms. These are denoted with ' 2 ' and ' 3 ' in the figure. Note that the sum of the organ equivalent doses in the risk organs (total height of bars) has no meaningful interpretation. 
Skin (mSv); \%

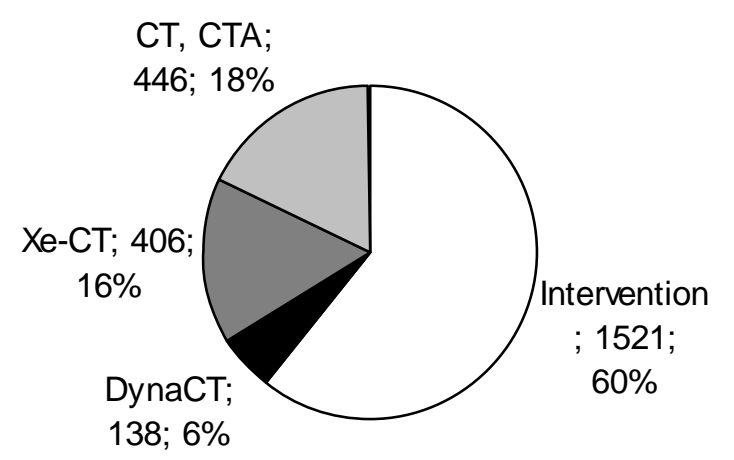

\section{Brain (mSv); \%}

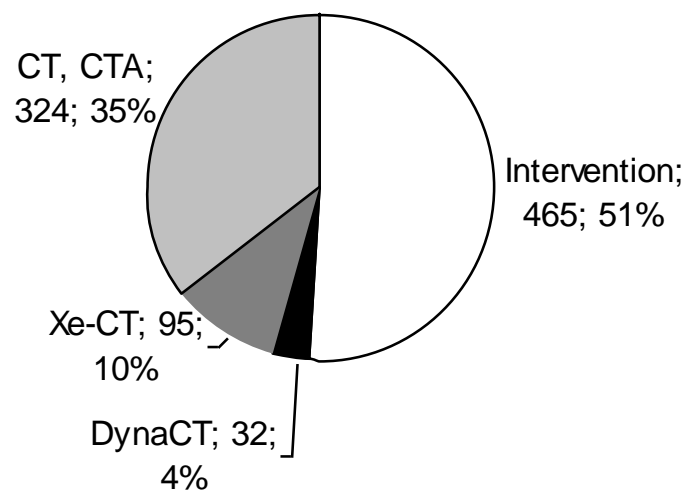




\section{Eye lens (mSv); \%}

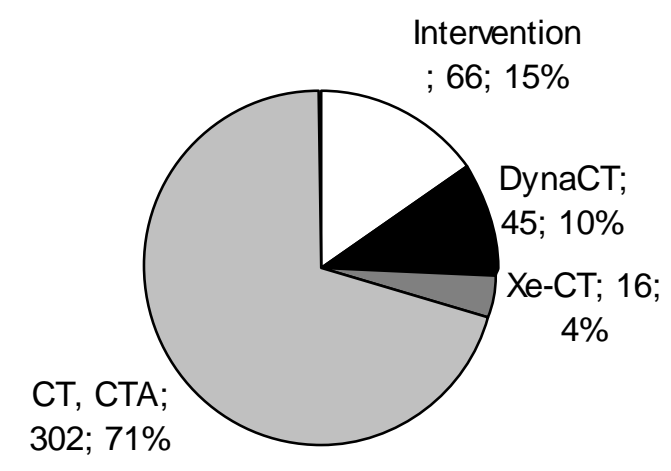

\section{Salivary gland (mSv); \%}

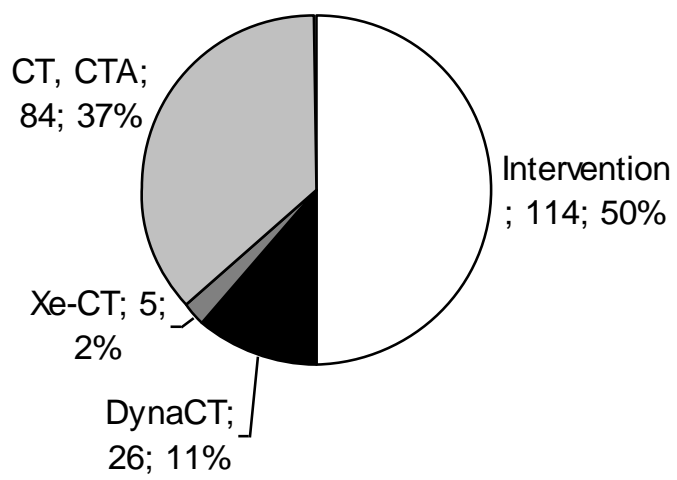

Figure 3. Pie charts of the organ equivalent doses in the skin (a), brain (b), eye lens (c), and salivary glands (d) and the corresponding percentages of the doses due to each type of imaging procedure. 